\title{
Dynamical coupling of PBPK/PD and AUC-based toxicity models for arsenic in tilapia Oreochromis mossambicus from blackfoot disease area in Taiwan
}

\author{
Chung-Min Liao ${ }^{\mathrm{a}, *}$, Huang-Min Liang ${ }^{\mathrm{a}}$, Bo-Ching Chen ${ }^{\mathrm{b}}$, \\ Sher Singh ${ }^{\mathrm{c}}$, Jeng-Wei Tsai ${ }^{\mathrm{a}}$, Yun-Hua Chou ${ }^{\mathrm{a}}$, Wen-Tze Lin ${ }^{\mathrm{d}}$ \\ ${ }^{a}$ Ecotoxicological Modeling Center, Department of Bioenvironmental Systems Engineering, National Taiwan University, \\ Taipei, Taiwan 10617, ROC \\ ${ }^{\mathrm{b}}$ Department of Post-Modern Agriculture, Mingdao University, Changhua, Taiwan 52345, ROC \\ ${ }^{\mathrm{c}}$ Center of Genomics Medicine, School of Medicine, National Taiwan University, Taipei, Taiwan 10617, ROC \\ ${ }^{\mathrm{d}}$ Environment Change Research Center, Academia Sinica, Nankang, Taipei, Taiwan 11517, ROC
}

Received 27 October 2003; accepted 5 November 2004

Integrated toxicity models can identify dynamic responses of fish to arsenic.

\begin{abstract}
A physiologically based pharmacokinetic and pharmacodynamic (PBPK/PD) models were developed for arsenic (As) in tilapia Oreochromis mossambicus from blackfoot disease area in Taiwan. The PBPK/PD model structure consisted of muscle, gill, gut wall, alimentary canal, and liver, which were interconnected by blood circulation. We integrate the target organ concentrations and dynamic response describing uptake, metabolism, and disposition of As and the associated area-under-curve (AUC)-based toxicological dynamics following an acute exposure. The model validations were compared against the field observations from real tilapia farms and previously published uptake/depuration experimental data, indicating that predicted and measured As concentrations in major organs of tilapia were in good agreement. The model was utilized to reasonably simulate and construct a dose-dependent dynamic response between mortality effect and equilibrium target organ concentrations. Model simulations suggest that tilapia gills may serve as a surrogate sensitive biomarker of short-term exposure to As. This integrated As PBPK/PD/ AUC model quantitatively estimates target organ concentration and dynamic response in tilapia and is a strong framework for future waterborne metal model development and for refining a biologically-based risk assessment for exposure of aquatic species to waterborne metals under a variety of scenarios.
\end{abstract}

(c) 2004 Elsevier Ltd. All rights reserved.

Keywords: Arsenic; Area-under-curve; Blackfoot disease; Modeling; Physiologically based pharmacokinetics; Pharmacodynamics; Tilapia

\footnotetext{
* Corresponding author. Tel.: +88622363 4512; fax: +88622362 6433.

E-mail address: cmliao@ntu.edu.tw (C.-M. Liao).
}

\section{Introduction}

Humans are exposed to arsenic (As) from many sources such as food, water, air and soil in that food is the major exposure source for As. The U.S. Food and Drug Administration (US FDA, 1993) in examining the food category indicated that fish and other 
seafood account for $90 \%$ of the total food As exposure with all other foods accounting for the remaining $10 \%$. Donohue and Abernathy (1999) reported that the total As in marine fish, shellfish, and freshwater fish tissues ranged from 0.19 to $65,0.2$ to 125.9 , and 0.007 to $1.46 \mu \mathrm{g} \mathrm{g}^{-1}$ dry wt, respectively. Koch et al. (2001) demonstrated that total As in freshwater fish ranged from 0.28 to 3.1 for Whitefish (Coregonus clupeaformis), 0.98 to 1.24 for Sucker (Catostomus commersoni), 0.46 to 0.85 for Walleye (Stizostedion vitreum), and 1.30 to $1.40 \mu \mathrm{g} \mathrm{g}^{-1}$ dry wt for Pike (Esox lucius), respectively.

Chen et al. (2001a) indicated that long-term exposure to ingested inorganic As in groundwater has been found to induce blackfoot disease (BFD), a unique peripheral vascular disease that ends with dry gangrene and spontaneous amputation of affected extremities in southwestern coastal area of Taiwan, consisting mainly of four towns, Putai, Yichu, Hsuehchia, and Peikangtzu located at Chiayi and Tainan counties. Recently, a number of studies on acquired and genetic susceptibility to As have been carried out in the BFD-endemic areas of southwestern Taiwan to find out the cause of BFD (Chen et al., 2001a). Nowadays, most of the people living in these areas do not drink water from groundwater because tap water has been made available in this area. However, groundwater is still used for aquaculture.

Lin et al. (2001), Singh (2001), and Liao et al. (2003) conducted a long-term investigation during 1998-2001 in BFD area which indicated that As have been detected in many aquacultural ponds in that As concentrations in aquacultural waters are reported to range from $26.3 \pm$ 16 to $251.7 \pm 12.2 \mu \mathrm{g}^{-1}$, whereas As concentrations in cultured fish ranged from $0.94 \pm 0.3$ to $15.1 \pm$ $8.2 \mu \mathrm{g} \mathrm{g}^{-1}$ dry wt. The results are much greater than the maximum contaminant level (MCL) for As in drinking water of $10 \mu \mathrm{g} 1^{-1}$.

Physiologically based pharmacokinetic and pharmacodynamic (PBPK/PD) models have been extensively used in risk assessment and prediction of pharmacokinetic and pharmacodynamic behavior in non-test mammals (Andersen et al., 1987; Reitz et al., 1990; Clewell, 1995; Clewell and Andersen, 1996). PBPK models have been developed in several aquatic species, e.g. cadmium in rainbow trout (Salmo gairdneir) (Thomann et al., 1997), paraoxon in rainbow trout (Oncorhynchus mykiss) (Abbas and Hayton, 1997), zinc in abalone (Haliotis diversicolor supertexta) (Liao et al., 2000), and waterborne organic chemicals in brook trout (Salvelinus fontinalis) (Nichols et al., 1998), and in lake trout (Salvelinus namaycush) (Lien et al., 2001). No PBPK in an aquatic animal, however, has related the toxicological effect to the target organ concentration, which would increase the significance of the model both for examination of the mechanism of toxicity of a chemical and for risk assessment.
Farming of tilapia (Oreochromis mossambicus) is a promising aquaculture in the BFD area because of high market value. The fish are fed with artificial bait, which does not contain As. If waterborne As levels are elevated, toxicity can occur and have severe effects on the health of cultured fish, which will reduce market prices and cause closure of fish farms. Its presence in the aquacultural environment directly threatens tilapia and consequently it poses a risk to human who consume exposed tilapia.

The objectives of the present paper are threefold: (1) to characterize the pharmacokinetics and pharmacodynamics of As after water exposure of tilapia, (2) to validate the PBPK/PD model against experimentally determined data by water exposure of tilapia to As and field measurements from real tilapia farms, and (3) to couple dynamically a PBPK/PD model and an areaunder-curve (AUC)-based acute toxicity model to construct concentration-response relationships.

In particular, we carried out one experiment and one field investigation with tilapia. One experiment involved in a 7-day acute toxicity bioassay to derive a PD model and organ-specific concentration-response profiles between mortality and equilibrium As concentrations. One field investigation conducted in real tilapia farms in BFD area to validate the proposed PBPK model. The integrated PBPK/PD and AUC models accounted for the uptake from water, its distribution into target organs, acute toxicity of As, and depuration of As from tilapia.

\section{Materials and methods}

\subsection{Sample collection and chemical analysis}

Tilapia (O. mossambicus) were collected from two fish ponds in Hsuehchia and three fish ponds in Yichu situated in the BFD area in the southwestern Taiwan region between August/November 1999 and January 2000. After the fish were stocked in the ponds, we used nylon nets to collect the samples of stocked tilapia from the fishponds. Fish samples were kept at $0{ }^{\circ} \mathrm{C}$ cooler and were transported to the laboratory as quickly as possible. Thus, five sets of fish samples from Yichu and Hsuehchia had been collected. Each time three $500 \mathrm{ml}$ water samples per pond were collected. One-liter polyethylene bottles cleaned with $10 \%$ nitric acid and then rinsed with deionized water were used as containers for the collection of water samples. The collected water was filtered through a $125 \mu \mathrm{m}$ nylon mesh to remove large suspended particles and macro-invertebrates immediately after collection, and then acidified by adding $5 \mathrm{ml}$ of $1 \mathrm{~N} \mathrm{HNO}_{3}$ before As analysis.

A Perkin-Elmer Model 5100PC atomic absorption spectrometer equipped with an HGA-300 graphite 
furnace atomizer was used to analyze As. Analytical quality control was achieved by digesting and analyzing identical amounts of rehydrated $\left(90 \% \mathrm{H}_{2} \mathrm{O}\right)$ standard reference material (Dog fish muscle, DORM-2, NRCCNRC, Canada). Recovery rate was $94.6 \pm 3.6 \%$ and the levels of detection were $0.62 \mu \mathrm{g} \mathrm{As} 1^{-1}$ for water samples and $0.05 \mu \mathrm{g} \mathrm{As} \mathrm{g}^{-1}$ for tissue samples.

\subsection{Acute toxicity bioassays}

Laboratory static bioassays were conducted to determine the 24-h, 48-h, 72-h, 96-h, 120-h, and 144-h $\mathrm{LC}_{50}$ values for tilapia exposed to As. The experimental design and calculations for the acute toxicity were based on well-known procedures given by Finney (1978) and Sparks (2000). The tests were carried out in 541 rectangular fiberglass aquaria of well-aerated and reconstituted dilution water $(\mathrm{pH} 7.8-8.0)$. The tested fish were collected from fish ponds in Taiwan Fisheries Research Institute, Lukang, Chunghwa. Six fish of a specific size class (mean body length $=17.67 \pm 1.65 \mathrm{~cm}$ (mean \pm SD) and mean body weight $=148.72 \pm 6.5 \mathrm{~g}$ wet $\mathrm{wt}$ ) were randomly selected and transferred into each test aquarium. Dissolved oxygen in each tank was maintained at close to saturation by aeration (7.19 \pm $0.03 \mathrm{mg}^{-1}$ ). The temperature in each aquarium was maintained at $24.3 \pm 0.32{ }^{\circ} \mathrm{C}$ using submerged heaters. The photoperiod was $16 \mathrm{~h}$ light: $8 \mathrm{~h}$ dark with an intensity of $1400 \pm 100$ lux.

The sodium arsenite $\left(\mathrm{NaAsO}_{2}\right)$ stock solution was prepared with deionized water. The fish were visibly free of any deformities, lesions or disease and acclimated in tap water for one week prior to experiment. The nominal concentrations of As tested were 0 (control), 1, 2, 4, 10, 30, 50, and $80 \mathrm{mgl}^{-1}$ (Hwang and Tsai, 1993). The measured As concentrations were $0.98 \pm 0.05,1.97 \pm$ $0.04,4.26 \pm 0.09,10.36 \pm 0.06,31.04 \pm 0.12,47.65 \pm$ 0.06 , and $81.53 \pm 0.08 \mathrm{mgl}^{-1}$. Gross mortality of fish to each concentration was recorded every $1 \mathrm{~h}$ for the first $12 \mathrm{~h}$ and every $2 \mathrm{~h}$ thereafter for $7 \mathrm{~d}$, and dead fish being removed every $1-2 \mathrm{~h}$. Tilapia were not fed throughout the test. Control and each test concentrations were tested in duplicate. No mortality occurred in the controls.

The $\mathrm{LC}_{50}$ values were determined from maximum likelihood estimates of linear functions relating $\log$ As concentration to probit transformations of percent mortality (Finney, 1978). The $\mathrm{LC}_{50}$ values were determined using mean assayed As concentrations and cumulative mortality. Statistical comparisons between $\mathrm{LC}_{50} \mathrm{~s}$ were based on the standard error of the difference. When it became apparent no statistically significant differences in $\mathrm{LC}_{50} \mathrm{~s}$ between bioassay replicates $(p>0.05)$, the replicates were pooled and a single $\mathrm{LC}_{50}$ was calculated for As. Chi-square tests were performed to test the homogeneity of mortality between replicates.

\subsection{PBPK model}

The essence of almost all PBPK models can be described by a linear dynamic equation

$\frac{\mathrm{d}\{C(t)\}}{\mathrm{d} t}=[K]\{C(t)\}+[B]\{q(t)\}$,

where $\{C(t)\}$ is a state variable vector which describes the chemical concentration in each assigned target organ, $\{q(t)\}$ represents an input vector of chemical concentration in ambient water, $[K]$ is a state matrix which describes the diffusion exchange rate between target organs, and $[B]$ is a constant input matrix which describes the exchange rate into target organs.

The following assumptions were made to develop the PBPK model: (i) there is a six-compartment pharmacokinetic model of blood-gill-muscle-gut wall-alimentary canal-liver representing actual anatomical units of tilapia, (ii) it is assumed that the gill acts as a continuousstirred tank reactor or well-mixed compartment into and out of which water flows, with chemical and oxygen being transferred to the tilapia based on diffusive mass transfer, (iii) a flow rate $Q_{i j} \geq 0$ gives the blood flow from the $j$ th blood compartment to the $i$ th organ compartment for $i \neq j$ with $1 \leq i, j \leq n$ in that all transport occurs through blood flows, (iv) there is a complete equilibrium of chemical between the blood phase and the tissue phase of each compartment and assumed that there is an inert soluble chemical with blood-chemical partitioning/binding coefficient $f_{i}$ present in amount of chemical partitioned to compartment tissue $i$, (v) there is a local mass balance of chemical substance in that for each compartment the amount of chemical substance entering is equal to the amount leaving, and (vi) there is a local mass balance of blood flow in that $\sum_{j=0, j \neq i}^{n} Q_{i j}=\sum_{j=0, j \neq i}^{n} Q_{j i}$ for $1 \leq i \leq n$.

For the compartment of gill that interacts with As in external water, additional process has to be considered (Thomann et al., 1997). An increased surface sorption to the gill surface was necessary. The exchange of As between internal gill tissue and the blood was therefore set at a lower exchange than the exchange between the gill surface and the water.

Based on Eq. (1) and our assumptions, we develop a linear PBPK model (Fig. 1) governing the principle features of the bioaccumulation and transport of As in tilapia in six target organs of blood, muscle, gill, gut wall, alimentary canal, and liver in that $\{C(t)\}=$ $\left\{C_{1}(t) C_{2}(t) C_{3}(t) C_{4}(t) C_{5}(t) C_{6}(t)\right\}^{T} \quad\left(\mathrm{~g} \mathrm{~g}^{-1}\right)$, respectively describes the As concentration in blood, muscle, gill, gut wall, alimentary canal, and liver; $\{q(t)\}=C_{w}$, the As 
concentration in ambient water $\left(\mu \mathrm{g} \mathrm{ml}^{-1}\right)$; the state matrix $[K]$ can be written as where $\mathrm{AUC}_{f}$ is the area under the whole body burden of As in tilapia versus time curve $\left(\mu \mathrm{g} \mathrm{d}^{-1}\right)$.

$\left[\begin{array}{cccccc}-\left(Q_{12}+Q_{13}+Q_{14}+Q_{15}+Q_{16}\right) \frac{f_{d}}{V_{1}} & \frac{Q_{12}}{f_{2} V_{1}} & \frac{Q_{13}}{f_{3} V_{1}} & \frac{Q_{14}}{f_{4} V_{1}} & \frac{Q_{15}}{f_{5} V_{1}} & \frac{Q_{16}}{f_{6} V_{1}} \\ \frac{Q_{21} f_{d}}{W_{2}} & -\left(\frac{Q_{21}}{f_{2} W_{2}}+k_{\mathrm{G}}\right) & 0 & 0 & 0 & 0 \\ \frac{Q_{31} f_{d}}{W_{3}} & 0 & -\left(\frac{Q_{31}}{f_{3} W_{3}}+\frac{Q_{3 W}}{f_{3} W_{3}}\right) & 0 & 0 & 0 \\ \frac{Q_{41} f_{d}}{W_{4}} & 0 & 0 & -\left(\frac{Q_{41}}{f_{4} W_{4}}+\frac{Q_{45}}{f_{4} W_{4}}\right) & \frac{Q_{45}}{f_{5} W_{4}} & 0 \\ \frac{Q_{51} f_{d}}{W_{5}} & 0 & 0 & \frac{Q_{54}}{f_{4} W_{5}} & -\left(\frac{Q_{51}}{f_{5} W_{5}}+\frac{Q_{54}}{f_{5} W_{5}}+\frac{W_{t}}{W_{5}} k_{\mathrm{E}}\right) & 0 \\ \frac{Q_{61} f_{d}}{W_{6}} & 0 & 0 & 0 & 0 & -\left(\frac{Q_{61}}{f_{6} W_{6}}+k_{\mathrm{M}}\right)\end{array}\right]$

and input constant matrix

$[B]=\left[\begin{array}{llllll}0 & 0 & \frac{Q_{3 W} \alpha_{3 W}}{W_{3}} & \frac{W_{t}}{W_{4}} k_{\mathrm{D}} & 0 & 0\end{array}\right]^{T}$,

where $Q_{i j}$ is the diffusive exchange rate between compartments $i$ and $j\left(\mathrm{~d}^{-1}\right), V_{1}$ is the blood volume (1), $f_{d}$ is the binding coefficient of As concentration to plasma proteins $\left(\mathrm{g}^{-1}\right), f_{i}=C_{i} / C_{\mathrm{d} i}$ is the partition coefficient or is referred to as a tissue/blood equilibrium distribution ration for linear binding in specific organ $i\left(\mathrm{~g} \mathrm{~g}^{-1}\right), C_{\mathrm{d} i}$ is the dissolved As concentration in compartment $i\left(\mathrm{~g}^{-1}\right), W_{i}$ is the time-independent tissue weight of compartment $i$ (g dry wt), $W_{t}$ is the whole fish body weight (g dry wt), $\alpha_{3 w}$ is the gill sorption factor representing enhancement of surface sorption, $K_{\mathrm{E}}$ is the elimination rate of fecal egestion $\left(\mathrm{g} \mathrm{g}^{-1} \mathrm{~d}^{-1}\right), K_{\mathrm{M}}$ is the metabolic transformation rate of $\mathrm{As}\left(\mathrm{g} \mathrm{g}^{-1} \mathrm{~d}^{-1}\right), K_{\mathrm{D}}$ is the As uptake rate from food $\left(\mathrm{g} \mathrm{g}^{-1} \mathrm{~d}^{-1}\right)$, and $K_{\mathrm{G}}$ is the tilapia growth dilution rate $\left(\mathrm{g} \mathrm{g}^{-1} \mathrm{~d}^{-1}\right)$.

\subsection{AUC-based toxicity model}

We employed an AUC-based toxicity model to estimate the internal residues of As in tilapia as a function of few constants and variables that were verified with acute toxicity data. The main factors are the exposure time, the exposure concentration, the bioconcentration factor $\left(\mathrm{BCF}=k_{1} /\left(k_{2}+k_{\mathrm{G}}\right)\right)$, the depuration rate constant $\left(k_{2}\right)$, where $k_{1}$ is the tilapia uptake rate constant of $\mathrm{As}\left(\mathrm{ml} \mathrm{g}^{-1} \mathrm{~d}^{-1}\right)$ and $k_{\mathrm{G}}$ is the growth rate constant $\left(\mathrm{d}^{-1}\right)$. The AUC-based toxicity model employed in determining the time-dependent median lethal concentrations $\left(\mathrm{LC}_{50}(t)\right)$ can be expressed as (Liao and Lin, 2001),

$\mathrm{LC}_{50}(t)=\frac{\mathrm{AUC}_{f}}{\mathrm{BCF}}\left(\frac{k_{2}+k_{\mathrm{G}}}{\left(k_{2}+k_{\mathrm{G}}\right) t+\mathrm{e}^{-\left(k_{2}+k_{\mathrm{G}}\right) t}-1}\right)+\mathrm{LC}_{50}(\infty)$,
Growth rate $\left(k_{\mathrm{G}}\right)$ can be calculated by fitting tilapia body weight data obtained from Reyes-Sosa and Castellanos-Molina (1995), Xie et al. (1997), and Takeuchi et al. (2002) to an exponential model (ln body weight $(W)=a+k_{\mathrm{G}} t$, where $a$ is a constant, $g$ is the growth rate $\left(\mathrm{d}^{-1}\right)$, and $t$ is the time in $\left.\mathrm{d}\right)$, resulting in a relationship of $k_{\mathrm{G}}=0.043 \exp (-0.012 W)\left(r^{2}=0.96\right)$.

$\mathrm{AUC}_{f}$ in Eq. (2) can be derived from the solution of a first-order one-compartment uptake-depuration model as,

$$
\begin{aligned}
\operatorname{AUC}_{f} & \equiv \int_{0}^{t} C_{f}(t) \mathrm{d} t=\int_{0}^{t} \operatorname{BCFC}_{w}\left(1-\mathrm{e}^{-\left(k_{2}+k_{\mathrm{G}}\right) t}\right) \mathrm{d} t, \\
& =\left(\frac{\mathrm{BCF}}{k_{2}+k_{\mathrm{G}}}\right) C_{w}\left(\left(k_{2}+k_{\mathrm{G}}\right) t+\mathrm{e}^{-\left(k_{2}+k_{\mathrm{G}}\right) t}-1\right),
\end{aligned}
$$

in that the first-order one-compartment uptakedepuration model is described as $\mathrm{d} C_{f}(t) / \mathrm{d} t=$ $k_{1} C_{w}-\left(k_{2}+k_{\mathrm{G}}\right) C_{f}(t)$ and its solution subject to the initial condition of $C_{f}(t=0)=0$ is $C_{f}(t)=$ $\operatorname{BCF} C_{w}\left(1-\mathrm{e}^{-\left(k_{2}+k_{\mathrm{G}}\right) t}\right)$. With sufficient $\mathrm{LC}_{50}(t)$ data, it is possible to calculate best-fit values of two toxicological parameters (i.e., $\mathrm{AUC}_{f}$ and $\mathrm{LC}_{50}(\infty)$ ) appeared in Eq. (2) by an nonlinear regression technique. Substitution of $C_{w}$ in one-compartment uptake-depuration model by $\mathrm{LC}_{50}(t)$ in Eq. (2) and by regarding $C_{f}(t)$ as the internal lethal body burden at the site of action that cause $50 \%$ mortality, $C_{L, 50}(t)$, leads to the following expression for $C_{L, 50}(t)$ as (Liao and Lin, 2001),

$$
\begin{aligned}
C_{L, 50}(t)= & \operatorname{AUC}_{f}\left(\frac{\left(k_{2}+k_{\mathrm{G}}\right)\left(1-\mathrm{e}^{-\left(k_{2}+k_{\mathrm{G}}\right) t}\right)}{\left(k_{2}+k_{\mathrm{G}}\right) t+\mathrm{e}^{-\left(k_{2}+k_{\mathrm{G}}\right) t}-1}\right) \\
& +\operatorname{BCF}\left(1-\mathrm{e}^{-\left(k_{2}+k_{\mathrm{G}}\right) t}\right) \mathrm{LC}_{50}(\infty) .
\end{aligned}
$$

Eq. (4) shows that the internal lethal body burden in tilapia can be expressed as functions of biokinetic parameters $k_{2}$ and $\mathrm{BCF}$, and growth rate $k_{\mathrm{G}}$, and toxicological parameters $\mathrm{AUC}_{f}$ and $\mathrm{LC}_{50}(\infty)$. When the 
A

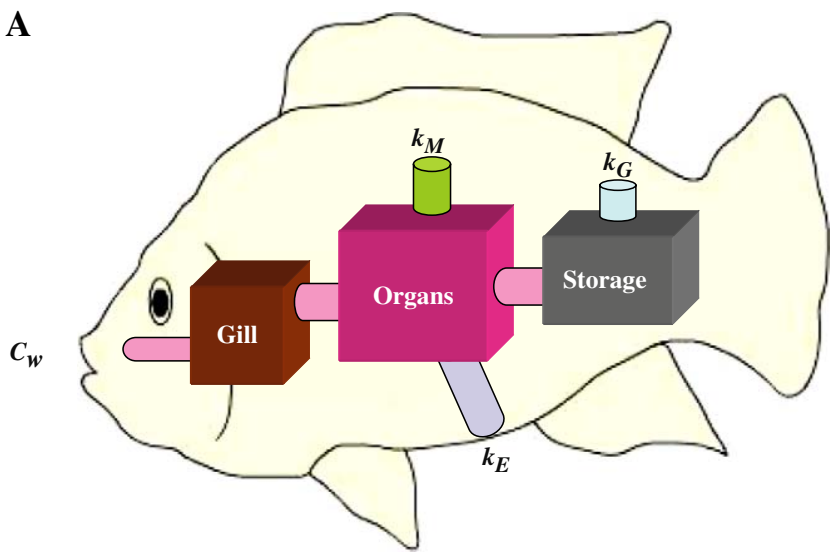

B

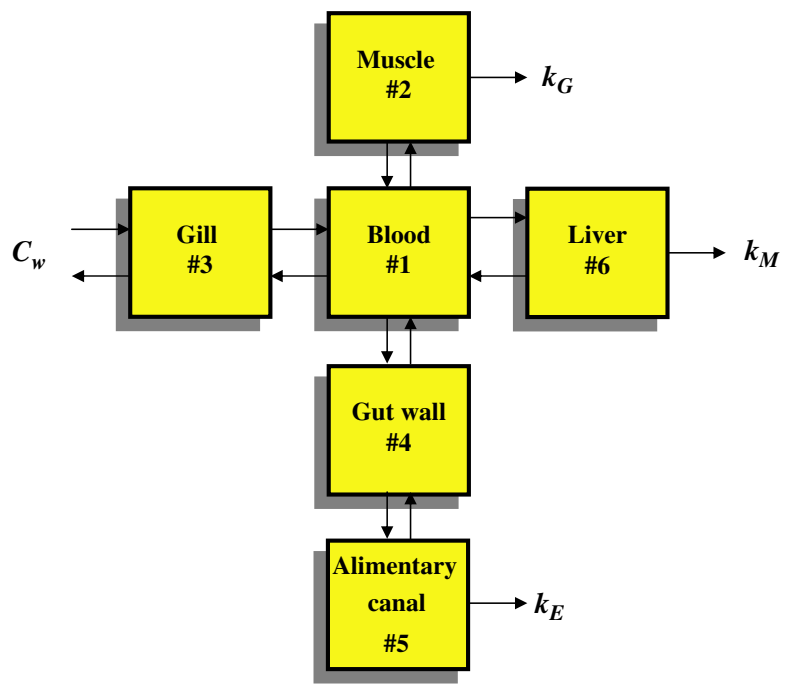

Fig. 1. Schematic diagram of physiologically based pharmacokinetic (PBPK) model for As in tilapia: (A) a compartment model showing the anatomical units of tilapia and (B) a PBPK model structure consisted of muscle, gill, gut wall, alimentary canal, and liver that interconnected by blood circulation.

exposure time approach infinity, Eq. (4) gives a relation among $\mathrm{LC}_{50}(\infty), C_{L, 50}(\infty)$ and $\mathrm{BCF}$ as

$C_{L, 50}(\infty)=\mathrm{LC}_{50}(\infty) \times \mathrm{BCF}$.

The AUC-based toxicity model in Eq. (2) is based on a direct relationship between adverse effects and extent of inhibited molecules in the target tissue, i.e. mortality is assumed to occur at a fixed percentage of inhibited molecules. Furthermore, the AUC-based toxicity model assumes that the concentration of inhibited molecules in the target tissue is constant, i.e. the percentage of lethal inhibited molecules is related to a critical amount of occupied target sites.

\subsection{PD model}

In pharmacodynamic modeling, the relationship between dose effect and dose concentration is commonly expressed by the Hill equation or is referred to as the sigmoid $E_{\max }$ model as (Lalonde, 1992; Bourne, 1995; de Vries, 1996),

$\operatorname{Effect}(E)=\frac{E_{\max } \times C^{n}}{\mathrm{EC}_{50}^{n}+C^{n}}$,

where $C$ is the dose concentration in the receptor, $E_{\max }$ is the maximum dose effect, $\mathrm{EC}_{50}$ is the concentration that causes an effect equal to $50 \%$ of the $E_{\max }$, and $n$ is a slope factor or is referred to as the Hill coefficient. The Hill equation in Eq. (6) is derived based on the receptor theory (Lalonde, 1992). With sufficient data over a suitable concentration range, it is possible to calculate bestfit values of three parameters appeared in Eq. (6) by nonlinear regression.

We combine Eqs. (4) and (6) incorporated with internal lethal body burden derived from TIC toxicity model to construct a dose-response profile. The mathematical model for the dose-response profile between mortality and As levels in different target organs of tilapia can be obtained by refining the Hill equation in Eq. (6) as: $E \equiv M, C \equiv C_{f}$ and $\mathrm{EC}_{50} \equiv C_{L, 50}(\infty)$ and associated with Eq. (5) as

$M_{i}=\frac{M_{\max } \times C_{f, i}^{n}}{C_{L, 50}^{n}(\infty)+C_{f, i}^{n}}=\frac{M_{\max } \times C_{f, i}^{n}}{\left(\mathrm{BCF}_{i} \times \mathrm{LC}_{50}(\infty)\right)^{n}+C_{f, i}^{n}}$,

where $M_{i}$ is mortality for tilapia in target organ $i, C_{f, i}$ is the internal As concentration in target organ $i, \mathrm{BCF}_{i}$ is the bioconcentration factor for target organ $i, M_{\max }$ is the tilapia maximum mortality exposed to waterborne As. We can now obtain a PD model describing waterborne As-dependent organ-specific time-mortality relationships as functions of As concentration in water $\left(C_{w}\right)$ and organ-specific toxicokinetic parameters $\left(k_{2}+k_{\mathrm{G}}\right.$, $\mathrm{BCF}$ ) and $\mathrm{LC}_{50}(\infty)$ by altering Eq. (7) to a timedependent function and associated with $C_{f}(t)$ in Eq. (1) for each target organ and $C_{L, 50}(t)$ in Eq. (4) as

$M(t)=\frac{M_{\max } \times C_{f}^{n}(t)}{C_{L, 50}^{n}(t)+C_{f}^{n}(t)}$.

Based on the acute toxicity test, however, mortality functions were estimated from observed mortality percentages in exposure regimes in which mortality was an increasing function of the As concentration in water. Therefore, in fitting the Hill equation to the observed mortality in terms of the specific interval acute toxicity data, the mortality functions used have to be expressed as the functions of waterborne As concentration $\left(C_{w}\right)$ and $\mathrm{LC}_{50}(t)$ data as,

$M(t)=\frac{M_{\max } \times C_{w}^{n}}{\mathbf{L C}_{50}^{n}(t)+C_{w}^{n}}$. 
With sufficient data of percent mortality over a suitable As concentration in water associated with the specific interval of $\mathrm{LC}_{50}$ data, we can estimate best-fit values of Hill coefficient appeared in Eq. (9) by nonlinear regression.

\subsection{Modeling and statistical analysis}

We performed all model exercises in Matlab version 5.2 (The Mathworks, Natick, Massachusetts, USA). All steady-state analytical solutions and eigenvalues were derived or checked using the appropriate Matlab Symbolic Math Toolbox functions. We could not determine time-dependent solutions analytically and thus integrated the differential equations numerically in Matlab.

The curve fitting was performed using the nonlinear regression option of the Statistica ${ }^{\circledR}$ software (StatSoft, Tulsa, OK, USA). We also employed Statistica ${ }^{\circledR}$ to determine the coefficient of determination $\left(r^{2}\right)$ and to perform statistical analyses including analysis of variance and Student's $t$-test. Statistical significance was determined if $p$ values were less than 0.05 .

\section{Results}

\subsection{Parameterization and application of PBPK model}

The PBPK model is composed of terms involving tilapia body size and biokinetics and terms involving physiological metal-specific processes. Input parameters for the model simulations were determined in the following way. The data for biokinetic parameters and tilapia properties were adopted from our research (Liao et al., 2003, 2004). Table 1 gives the weights of target organs and key biokinetic parameters used in model implementation.

It is not possible to estimate all of the physiological parameters for the model independently of the experimental data because individual experiments for tilapia were not available. It is possible, however, to estimate from the literature, the order of parameters for the various organs and the fraction of As in the blood in the available plasma form. Therefore, a preliminary database adapted from Thomann et al. (1997) regarding the trace cadmium bioaccumulation in rainbow trout is used to estimate a range of physiological model parameters. Results obtained from the model simulation via the preliminary database are compared to the laboratory uptake and depuration data obtained from Liao et al. (2004) for tilapia exposed to waterborne As and field observations from BFD area to calibrate the physiological parameters in order to estimate a consistent set of parameters.
Table 1

Tilapia properties and biokinetic parameters used for PBPK model simulation

\begin{tabular}{|c|c|c|c|}
\hline \multirow[t]{2}{*}{ Symbol } & Estimated value & Units & Description \\
\hline & \multicolumn{3}{|l|}{ Mean \pm SD } \\
\hline \multicolumn{4}{|c|}{ Tilapia properties ${ }^{\mathrm{a}}$} \\
\hline$W_{t}$ & $208 \pm 32$ & $\mathrm{~g}$ & Dry weight of whole fish \\
\hline$V_{1}$ & $0.02 \pm 0.002$ & 1 & Blood volume \\
\hline$W_{2}$ & $154.75 \pm 18.24$ & $\mathrm{~g}$ & Dry weight of muscle \\
\hline$W_{3}$ & $10 \pm 1.02$ & $\mathrm{~g}$ & Dry weight of gill \\
\hline$W_{4}$ & $5 \pm 0.75$ & $\mathrm{~g}$ & Dry weight of gut wall \\
\hline$W_{5}$ & $12 \pm 1.25$ & $\mathrm{~g}$ & $\begin{array}{l}\text { Dry weight of } \\
\text { alimentary canal }\end{array}$ \\
\hline$W_{6}$ & $5 \pm 0.42$ & $\mathrm{~g}$ & Dry weight of liver \\
\hline \multicolumn{4}{|c|}{ Biokinetic parameters } \\
\hline$k_{\mathrm{D}}$ & 0 & $\mathrm{~g} \mathrm{~g}^{-1} \mathrm{~d}^{-1}$ & $\begin{array}{l}\text { Food ingestion rate } \\
\text { of fish per day }\end{array}$ \\
\hline$k_{\mathrm{E}}$ & $2.0 \times 10^{-3}$ & $\mathrm{~d}^{-1}$ & Egestion rate ${ }^{b}$ \\
\hline$k_{\mathrm{G}}$ & $6.7 \times 10^{-3}$ & $\mathrm{~d}^{-1}$ & Growth rate \\
\hline$k_{\mathrm{M}}$ & $8.8 \times 10^{-2}$ & $\mathrm{~d}^{-1}$ & Metabolic rate of As in liver ${ }^{\mathrm{d}}$ \\
\hline \multicolumn{4}{|c|}{$\begin{array}{l}{ }^{\mathrm{a}} \text { Measured from field tilapia samples. } \\
\mathrm{b} \text { Adopted from previously published uptake/depuration bioassay } \\
\text { (Liao et al., 2004). } \\
{ }^{\mathrm{c}} \text { Calculated from } k_{\mathrm{G}}=0.043 \exp \left(-0.012 W_{2}\right) \text { for an average tilapia } \\
\text { muscle dry weight of } W_{2}=154.75 \mathrm{~g} \text { wet wt. } \\
{ }^{\mathrm{d}} \text { Calculated from } k_{\mathrm{M}}=\ln 2 /\left(\ln 2 / k_{2}\right) \text { in that } k_{2}=8.8 \times 10^{-2} \mathrm{~d}^{-1} \\
\text { for liver (Liao et al., 2004). }\end{array}$} \\
\hline
\end{tabular}

An initial set of parameters was estimated and then modified to reproduce the observed uptake and depuration characteristics for tilapia. The remaining parameters for the other organs were also carefully calibrated simultaneously to meet the favorable agreement against the observed and experimental data. It is recognized that the final set of parameters used to calibrate the data are hardly unique, but the parameter set is believed to represent a reasonable estimation for the model as a whole. Blood exchange flow rates to the various organs were not available in the literature for the tilapia. The estimates of the exchange flow rates shown in Table 2 therefore are based on the data of Thomann et al. (1997) where the exchange rates to various organs were carefully calibrated and were taken as being proportional to exchange flow on a $1 \mathrm{~d}^{-1}$ basis in the same proportional as that seen in rainbow trout.

Figs. 2 and 3, respectively display the results of the model comparisons to the measured data of the temporal profiles obtained from the laboratory uptake and depuration experiment and real tilapia farms in BFD area. The PBPK predictions were considered to agree with experimentally determined values and field measurements of the concentration-time profiles of As in various organs if they were within one standard deviation of the mean. In addition, the goodness-of-fit was evaluated using root-mean-squared-error (RMSE), computed from $\mathrm{RMSE}=\sqrt{\sum_{n=1}^{N}\left(C_{\mathrm{m}, n}-C_{\mathrm{s}, n}\right)^{2} / N}$ where $N$ denotes the number of measurements, $C_{\mathrm{m}, n}$ is the measurement data, and $C_{\mathrm{s}, n}$ is the simulation result 
Table 2

Physiologically based parameters used for PBPK model simulation

\begin{tabular}{llll}
\hline Symbol & $\begin{array}{l}\text { Estimated } \\
\text { value }\end{array}$ & Units & Description \\
\hline$Q_{3 w}$ & 0.01 & $1 \mathrm{~d}^{-1}$ & Gill-water exchange rate \\
$Q_{12}$ & 2.5 & $1 \mathrm{~d}^{-1}$ & Blood-muscle exchange rate \\
$Q_{13}$ & 0.2 & $1 \mathrm{~d}^{-1}$ & Blood-gill exchange rate \\
$Q_{14}$ & 7.5 & $1 \mathrm{~d}^{-1}$ & Blood-gut wall exchange rate \\
$Q_{15}$ & 0.5 & $1 \mathrm{~d}^{-1}$ & Blood-alimentary canal exchange rate \\
$Q_{16}$ & 3.6 & $1 \mathrm{~d}^{-1}$ & Blood-liver exchange rate \\
$Q_{45}$ & 1.4 & $1 \mathrm{~d}^{-1}$ & Gut wall-alimentary canal exchange rate \\
$\alpha_{3 w}$ & 8 & - & Gill sorption factor \\
$f_{d}$ & 0.2 & $\mathrm{~g}^{-1}$ & Fraction As dissolved in blood \\
$f_{2}$ & 5.2 & $1 \mathrm{~g}^{-1}$ & Partition coefficient of muscle \\
$f_{3}$ & 0.04 & $1 \mathrm{~g}^{-1}$ & Partition coefficient of gill \\
$f_{4}$ & 8.3 & $1 \mathrm{~g}^{-1}$ & Partition coefficient of gut wall \\
$f_{5}$ & 4.6 & $1 \mathrm{~g}^{-1}$ & Partition coefficient of alimentary canal \\
$f_{6}$ & 5.2 & $1 \mathrm{~g}^{-1}$ & Partition coefficient of liver \\
\hline
\end{tabular}

${ }^{\text {a }}$ Calibrated from experimentally determined data adopted from Liao et al. (2004) and field observations conducted in the present research.

corresponding to data point $n$. Table 2 lists the final set of physiological parameters used for tilapia in the model implementation.

Table 3 lists the RMSE values for the model performances, indicating that each RMSE value is less than 1 SD of gill, liver, alimentary canal, and muscle during uptake/depuration experiment as shown in Fig. 2. The results demonstrate that the PBPK model simulated values agreed with the experimentally determined concentration-time profiles of As in various target organs after water exposure. The predicted values were within the error limits of the field observations and the RMSE values were less than 1 SD in liver, as shown in Fig. 3. The field measured time courses of the organ concentrations of As indicated that the variability and uncertainty exists in tilapia and aquatic environment.

Fig. 4 shows the exposure profiles of As concentrations in various target organs of tilapia using PBPK model with exposure for a period of $300 \mathrm{~d}$ simulation with a measured average water As concentration of $0.094 \mu \mathrm{g} \mathrm{ml}^{-1}$ in selected tilapia farms. Fig. 4 indicates that the gill is calculated to reach a steady-state at about 10th d, whereas at within 100th d for blood and liver and 150th d for gut wall and alimentary canal. A steady-state As concentration in muscle is reached after 240 th d.

\subsection{Dynamical coupling of AUC toxicity and PBPK/PD models}

The selected time intervals of 24-h, 48-h, 72-h, 96-h, $120-\mathrm{h}$, and $144-\mathrm{h} \mathrm{LC}_{50}$ values with $95 \% \mathrm{CI}$ of As to tilapia are given in Table 4 . $\mathrm{LC}_{50}$ lowers progressively as the duration of exposure increases. A limited number of studies have investigated As toxicity to tilapia. Our 96-h $\mathrm{LC}_{50} \mathrm{~s}$ of As to tilapia is 28.68 (95\% CI: 24.92-32.44) $\mathrm{mg} 1^{-1}$, and is closed to the range of $96-\mathrm{h} \mathrm{LC}_{50}$ of As to seawater tilapia $\left(26.5 ; 95 \% \mathrm{CI}: 23.2-33.8 \mathrm{mg}^{-1}\right)$, yet lower than that of As to freshwater tilapia $(71.7 ; 95 \%$ CI: $67.8-76.4 \mathrm{mgl}^{-1}$ ) reported by Hwang and Tsai (1993).

The optimal fit of the AUC-based toxicity model to the $\mathrm{LC}_{50}(t)$ data listed in Table 4 are presented in Fig. 5. The input parameters used are whole-body $k_{2}=0.077$ $\mathrm{d}^{-1}$ (Liao et al., 2004) and $g=0.0067 \mathrm{~d}^{-1}$ based on an average tilapia weight of $154.75 \mathrm{~g}$ wet wt. The estimated values for $\mathrm{LC}_{50}(\infty)$ and $\mathrm{AUC}_{f} / \mathrm{BCF}$ are $25.55 \mathrm{mg} \mathrm{l}^{-1}$ and $46.36\left(\mathrm{mg} \mathrm{d}^{-1}\right) /\left(\mathrm{kg}^{-1}\right)$, respectively. The coefficients of determination $\left(r^{2}\right)$ indicate the quality of the fit for the AUC-based toxicity model $\left(r^{2}=0.80\right.$, $p<0.05$ ).

A dose-response relationship between equilibrium As concentration in each target organ of tilapia and mortality was derived using Eq. (7) and estimate of Hill coefficient ( $n$ ) obtained from optimal fitting to Eq. (9) by nonlinear regression. The optimal fits of Eq. (9) to the observed percent mortality of tilapia versus waterborne As concentration of the 96-h acute toxicity test is presented in Fig. 6, resulting in the estimated Hill coefficient, $n=4.07\left(r^{2}=0.93, p<0.05\right)$. Fig. 7 illustrates a clear dose-response relationship between internal As concentration in each target organ of tilapia and mortality. Fig. 7 shows that muscle and gill have a relative steep sigmoid dose-response profile with mortalities approaching $100 \%$, whereas gut wall, blood, and liver have a lazy sigmoid dose-response profile. The median internal effect concentration $\left(\mathrm{IEC}_{50}\right)$ and $\mathrm{IEC}_{10}$ for muscle and gill are 350 and 400; and 200 and $250 \mu \mathrm{g} \mathrm{g}^{-1}$ dry wt, respectively, whereas for gut wall are 700 and $450 \mathrm{gg} \mathrm{g}^{-1}$ dry wt, respectively. The U.S. Environmental Protection Agency (US EPA, 2000) recommended that IEC $_{10}$ could be used as a surrogate threshold of regulatory endpoint in ecological risk assessment.

We substitute $C_{f}(t)$ of organ-specific As concentrations from Eq. (1) and $C_{L, 50}(t)$ in Eq. (4) into Eq. (8) to obtain a PD model describing the time-mortality profiles as functions of toxicokinetic parameters $\left(k_{2}+k_{\mathrm{G}}\right.$, $\mathrm{BCF}$, and $\left.\mathrm{LC}_{50}(\infty)\right)$ at certain waterborne As concentration. Therefore, dynamical coupling of the PBPK and PD models with AUC-based toxicity model can obtain a representation as shown in Fig. 8 in that time-concentration, time-mortality, and concentration-mortality profiles reveal a whole picture of this study.

\section{Discussion}

\subsection{Waterborne arsenic toxicity to tilapia}

Because few previous studies have evaluated As toxicity to tilapia, we did not have an a priori estimate 

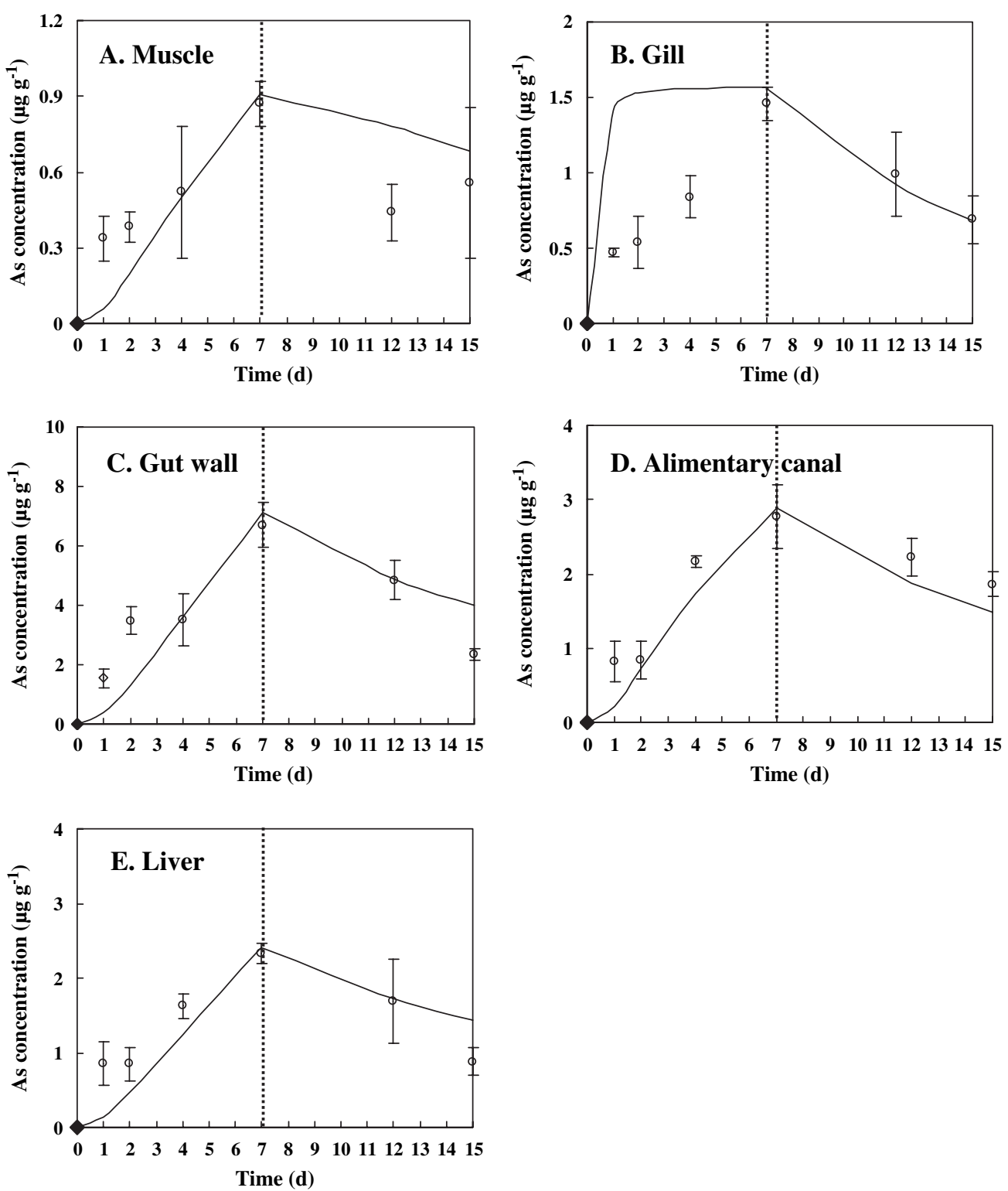

Fig. 2. Concentration-time profiles of As in (A) muscle, (B) gill, (C) gut wall, (D) alimentary canal, and (E) liver during a 7-day uptake of tilapia to a $1 \mu \mathrm{g} \mathrm{ml}^{-1}$ solution of As and followed by a 8-day depuration in As-free water. Points represent experimentally determined values and lines depict computer simulation of the PBPK model. Each point represents the mean $\pm 1 \mathrm{SD}$ of three fish.

of internal lethal body burdens. Mechanisms of As toxicity in tilapia have not been investigated extensively. Several studies have reported acute toxicity of As to other fish species. Our result of the $96-\mathrm{h} \mathrm{LC}_{50}$ As $(95 \%$ CI: $24.92-32.44 \mathrm{mgl}^{-1}$ ) for tilapia is closed to the range of 96-h $\mathrm{LC}_{50}$ As to rainbow trout O. mykiss (23$26.6 \mathrm{mg}^{-1}$ ) (Spehar et al., 1980) and to bluegill Lepomis macrochirus (29-35 $\mathrm{mg}^{-1}$ ) (Johnson and Finley, 1980).

Chen et al. (2001b) indicated that tilapia could potentially be able to regulate the concentrations of metals in their organs with time by combining the processes of absorption, excretion, detoxification and storage, and this can be checked by analyzing the organs of individuals exposed to different metals for different periods of time. In addition, the rate of metal uptake was organ-specific and time-dependent in fish. Our results demonstrate that most of the As was accumulated in the alimentary canal, liver, and gut wall of tilapia than in the muscle. Suner et al. (1999) also stated that fish liver contains more As than muscle, for total As as well as for inorganic As. Many laboratory and field studies have revealed that many trace metals $(\mathrm{Zn}, \mathrm{Cu}$, $\mathrm{Cr}, \mathrm{Ni}, \mathrm{Hg}, \mathrm{Cd}, \mathrm{Pb}$ ) were accumulated in alimentary canal/gut wall/liver than in muscle of tilapia (Kureishy and D'silva, 1993; Liang et al., 1999), demonstrating that alimentary canal/gut wall/liver play a vital role in storing As in tilapia. Suhendrayatna et al. (2002) further suggested that tilapia could be used as a bioindicator for studying the accumulation and transformation of As in freshwater organisms. 

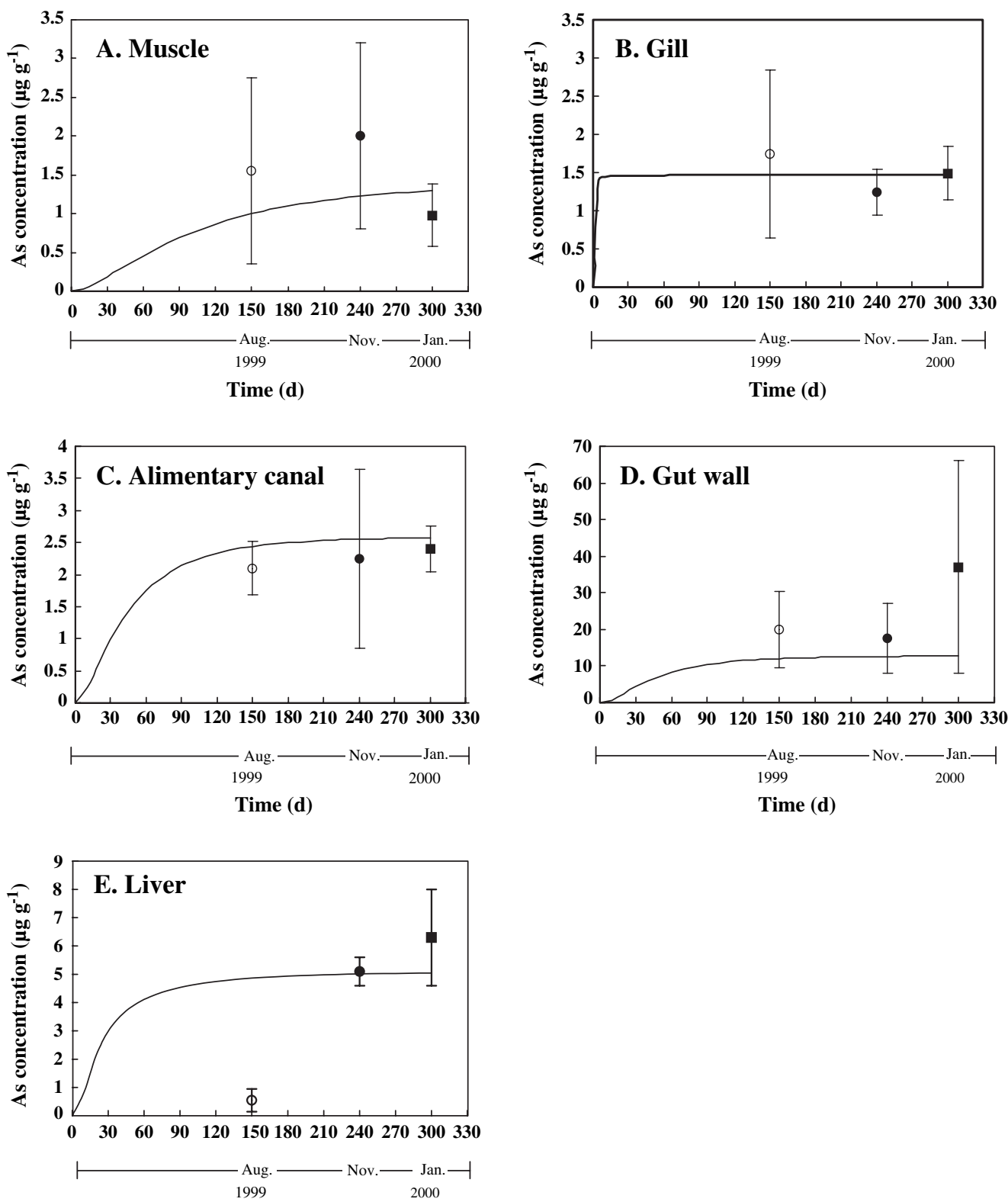

Time (d)

Fig. 3. Concentration-time profiles of As in (A) muscle, (B) gill, (C) gut wall, (D) alimentary canal, and (E) liver during field sampling between August/November 1999 and January 2000 in the BFD area in the southwestern Taiwan region. Points represent field observations and lines depict computer simulation of the PBPK model. Each point represents the mean \pm 1 SD in that $n=6$ for open circle and $n=15$ for closed circle and closed square.

\subsection{Internal effect concentration-time responses}

The fit of the AUC-based TIC toxicity model may be strongly determined by the input parameters. Therefore, uncertainties in the $k_{2}$ and $g$ values, which are input parameters in the AUC-based toxicity model, affect the validation of the model. Generally, the experimental $\mathrm{LC}_{50}(t)$ data for tilapia exposed to waterborne As

Table 3

Root-mean-squared-error (RMSE) ( $\left.\mu \mathrm{g} \mathrm{g}^{-1}\right)$ between measured concentration $\left(C_{\mathrm{m}}\right)$ and simulated concentration $\left(C_{\mathrm{s}}\right)$ in various organs of tilapia

\begin{tabular}{llllll}
\hline Measured data & Gill & Liver & Gut wall & Alimentary canal & Muscle \\
\hline Uptake/depuration experiment $_{\text {Field investigations }}$ & $0.63(0.15)^{\mathrm{a}}$ & $0.43(0.26)^{\mathrm{a}}$ & $0.37(0.54)^{\mathrm{a}}$ & $1.22(0.42)^{\mathrm{a}}$ & $0.58(0.15)^{\mathrm{a}}$ \\
& $0.21(0.58)^{\mathrm{b}}$ & $0.89(0.87)^{\mathrm{b}}$ & $15.0(16.33)^{\mathrm{b}}$ & $0.28(0.72)^{\mathrm{b}}$ & $0.20(0.93)^{\mathrm{b}}$
\end{tabular}

a The $1 \mathrm{SD}$ value of uptake/depuration experiment shown in Fig. 2.

b The $1 \mathrm{SD}$ value of field investigations shown in Fig. 3. 


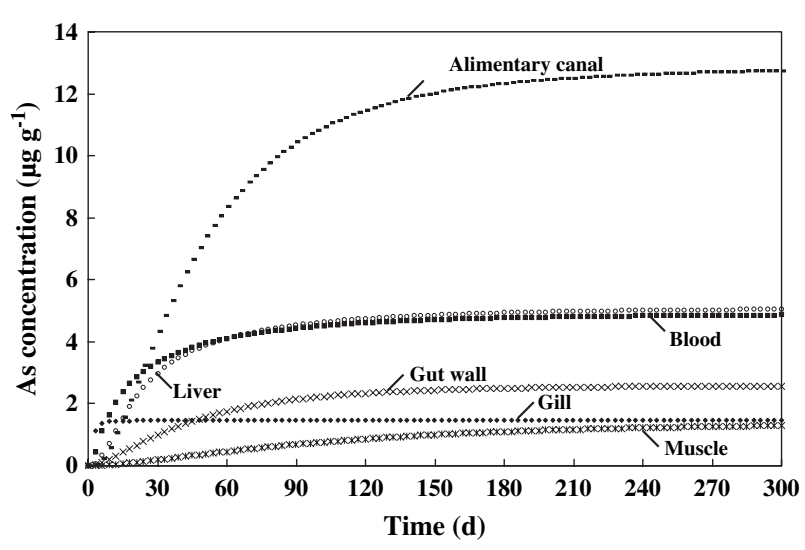

Fig. 4. Calculated PBPK model simulation for time course of As concentrations in the major organs of tilapia at an average level of field condition of water As concentration of $0.094 \mu \mathrm{g} \mathrm{ml}^{-1}$ measured in tilapia farms.

support the validity of the AUC-based toxicity model, despite the uncertainties in the input parameters $k_{2}$ and $g$ values. Our analysis suggests that the use of constant whole body burden for each individual mode of action as an interpretive and regulatory tool in the environmental risk assessment of waterborne metals might be limited to mode of actions.

Hermens (1989) and McCarty and Mackay (1993) also suggested that the concept of the whole body burden might not hold for chemicals exhibiting an irreversible adverse effect. A specific model of action, however, could also be complicated and misleading in estimating ecosystem concentrations and comparing these concentrations with $\mathrm{LC}_{50}$ data. McCarty and Mackay (1993) also pointed out that the constant whole body burden with respect to time and species for chemicals indicating the same mode of action; thus the whole body burden toxicity concept differs from the concept of the AUC-based toxicity model employed.

The time-mortality profiles can be expressed as the functions of $\mathrm{BCF}, k_{2}+k_{\mathrm{G}}, \mathrm{LC}_{50}(\infty)$, and $\mathrm{AUC}_{f}$. Our work uses the AUC-based toxicity concept to derive the internal effect concentration-time response relationships for each target organ under a specific waterborne As exposure, which can be applied to time-mortality data, and estimated toxicological parameters from the results

Table 4

$\mathrm{LC}_{50}$ of arsenic to tilapia for selected time intervals in which values of $95 \%$ confidence interval $(\mathrm{CI})$ are given in parentheses

\begin{tabular}{ll}
\hline Time $(\mathrm{h})$ & $\mathrm{LC}_{50}\left(\mathrm{mg} \mathrm{l}^{-1}\right)$ \\
\hline 24 & $69.06(65.81-72.31)$ \\
48 & $51.52(48.11-54.93)$ \\
72 & $38.44(34.85-42.03)$ \\
96 & $28.68(24.92-32.44)$ \\
120 & $21.41(17.59-25.23)$ \\
144 & $15.98(12.07-19.89)$ \\
\hline
\end{tabular}

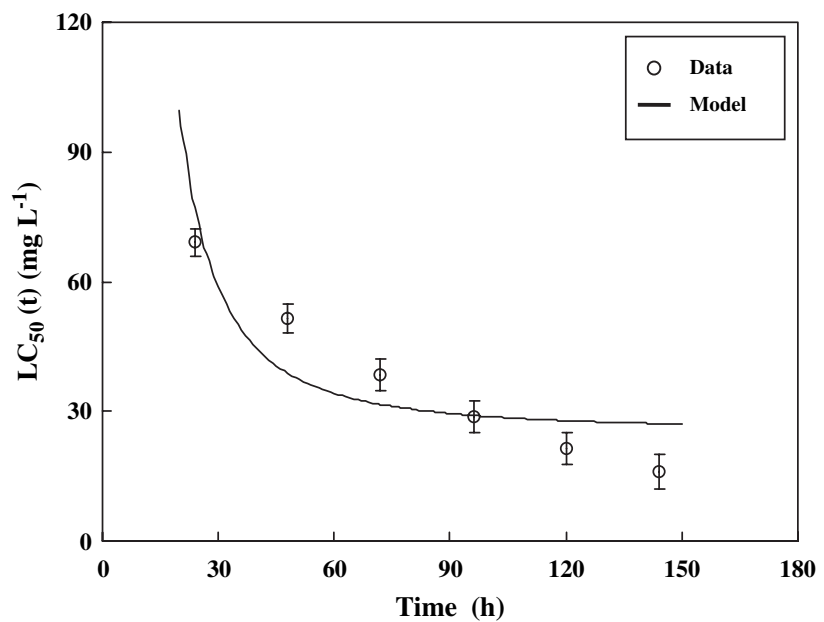

Fig. 5. Optimal fit of the AUC-based toxicity model to the $\mathrm{LC}_{50}(t)$ data (mean $\pm 95 \% \mathrm{CI}$ ) listed in Table 4 .

in the traditional bioassay. Our results strongly suggest the applicability of the AUC-based toxicity concept since it demonstrates that the toxicity is indeed dependent on the AUC of each target organ of tilapia. Therefore, a one-compartment first-order toxicokinetic model coupling with an AUC-based toxicity model can describe and predict the time course of As toxicity to tilapia.

\subsection{PBPK and AUC-based PD models}

The utility of a PBPK model derives from the fact that model structure and parameterization are based largely upon real anatomical, physiological, and biochemical attributes. The model structure also reflects the basic assumptions concerning factors that control chemical flux among organs and between the organism and its environment. Correspondence between predicted and measured values provides support for these

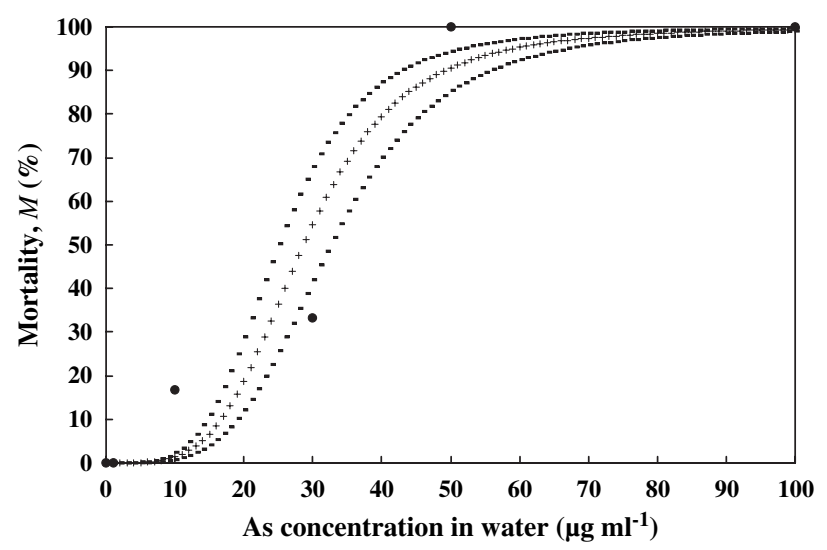

Fig. 6. Optimal fit of the PD model to observed percent mortality of tilapia versus waterborne As concentration in the 96-h acute toxicity bioassay. 


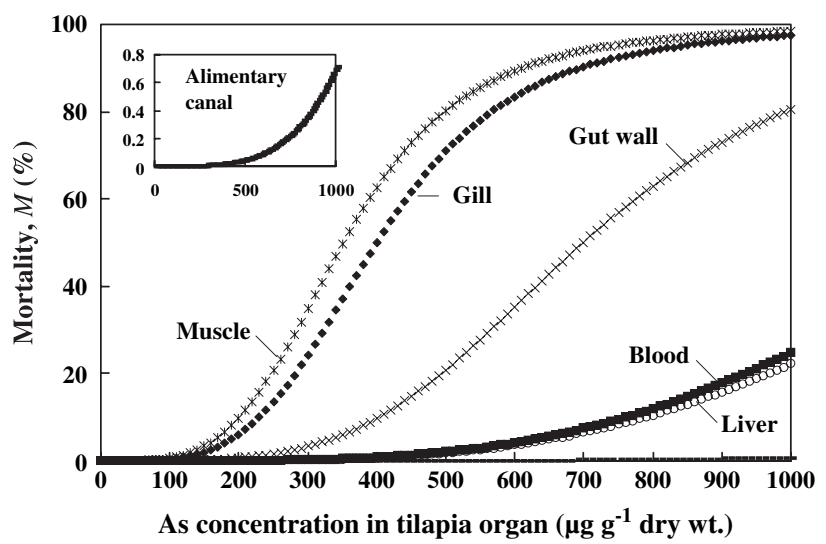

Fig. 7. Calculated PD model simulation for constructing organ-specific dose-response relationships between equilibrium internal effect concentration of As and mortality effect of tilapia.

assumptions as well as estimated values of important physiological parameter inputs. Accepting these assumptions, it then becomes possible to use the model to simulate hypothetical exposure scenarios.

A receptor theory-based PD model represented by a modified Hill equation is used to construct doseresponse relationships between organ-specific equilibrium As concentrations in tilapia and their mortality effects
(Bourne, 1995; de Vries, 1996). Therefore, by dynamical coupling of an appropriate PBPK model (i.e., the time course of accumulation of the waterborne As) and an AUC-based PD model (i.e., the time course of the adverse biological response by each target site of tilapia to the accumulated As), the complete dose-response profiles and duration of effect can be predicted for aquatic biota exposed to any waterborne metal.

The organ-specific dose-response relationships determined in this study indicate that gill has a more steep sigmoid profile than that of liver (Fig. 7); indicating that gill is a more sensitive organ than liver response to tilapia exposed to waterborne As. The organ-related difference in the mortality dose-response observed in this study is noteworthy. The gill is an important site of accumulation for many transition metals (Sorensen, 1991) and also many organic pollutants (Landrum et al., 1996). Furthermore, the gills are the primary sites of toxicity, metal-induced mortality in freshwater fish occurring through the distribution of branchial ion regulation (Lauren and McDonald, 1987a,b). Under these conditions, the gill appears to be a sensitive biomarker of short-term As exposure and a more robust biomarker of As exposure than the liver, alimentary canal, and gut wall. Parsimoniously, tilapia gill may serve as a surrogate sensitive biomarker of short-term exposure to waterborne As.

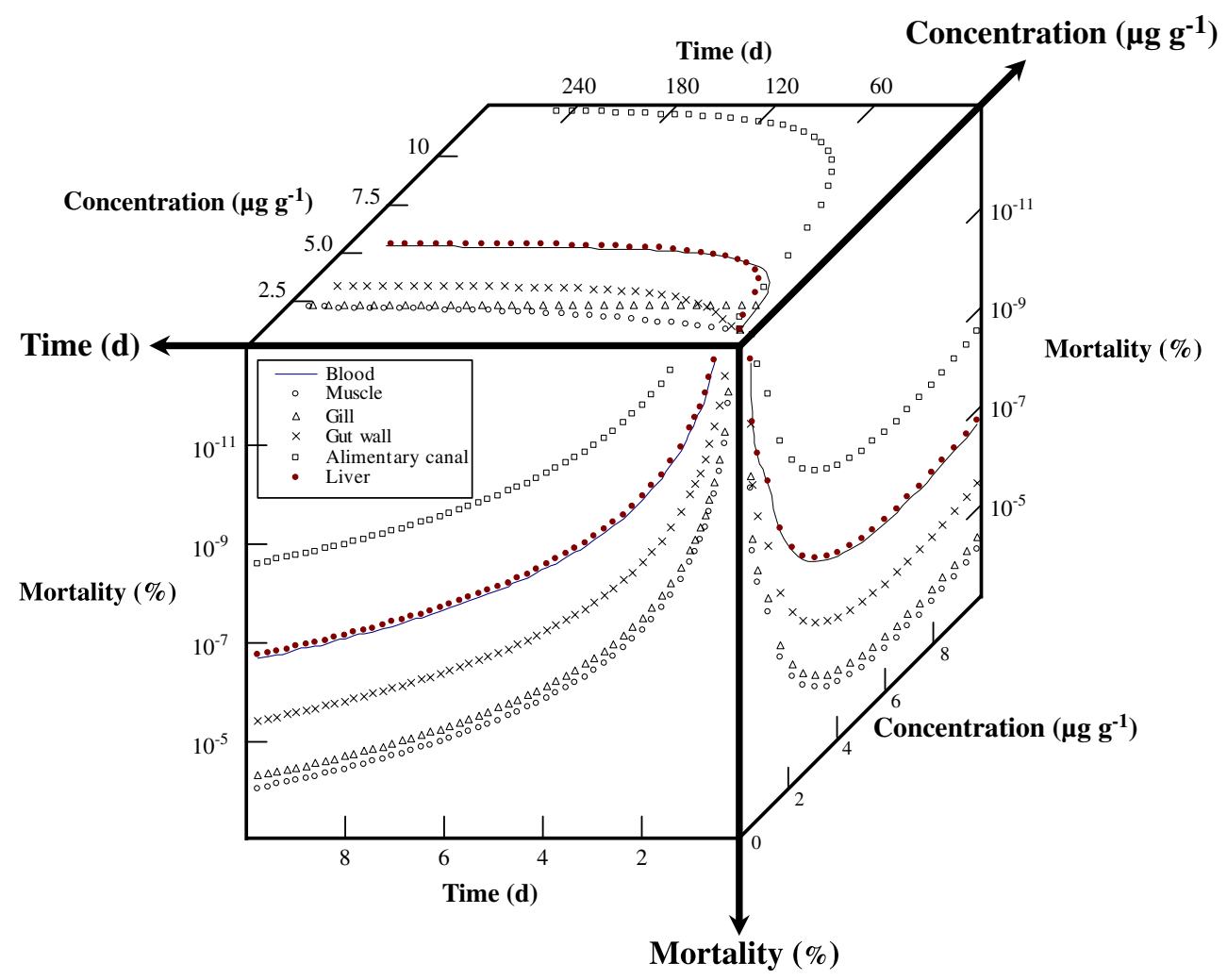

Fig. 8. An integrated $\mathrm{PBPK} / \mathrm{PD} / \mathrm{AUC}$ model simulation for the target organs of tilapia exposed to waterborne As at levels of experimental conditions. 
The PBPK/PD model that was developed for As is capable of quantitating target organ concentrations and dynamic response in tilapia, and is a useful tool to quantitatively assess risk associated with As exposure as well as helping to design and focus future experimental research. The capability of the model to accurately predict concentration and response is limited adequately by the model parameters and limitations of the experimental data.

The development and validation of a PBPK/PD model is an iterative process and reflects the current limitations of our understanding of critical biological processes that help identify important data gaps. Additional studies are needed to better understand and to characterize the time course and dose response for inhibition mechanisms, since this PD response is particularly relevant as a potential biomarker for exposure. Our proposed As PBPK/PD model in tilapia linking dynamically of AUC-based toxicology model quantitatively estimates target organ concentrations and dynamic response, and is an effective framework for future metal development in aquatic species, and for establishing a biologically-based risk assessment for metal exposure under a variety of scenarios.

In conclusion, this model contributes to a better understanding of the fundamental processes that regulate the uptake, metabolism, and disposition of As in tilapia. This information is crucial in developing a better understanding of dynamic relationships between concentration exposure and hazard to tilapia and human who consume the contaminated fish.

\section{Acknowledgements}

The authors wish to acknowledge the financial support of the National Science Council under the Grant NSC 92-2313-B-002-031. Thanks are also due the fish farm owners for providing valuable information and for permitting us the use of their fish farms, without which this research work would have not been possible.

\section{References}

Abbas, R., Hayton, W.L., 1997. A physiologically based pharmacokinetic and pharmacodynamic model for paraoxon in rainbow trout. Toxicol. Appl. Pharmacol. 145, 192-201.

Andersen, M.E., Clewell III, H.J., Gargas, M.L., Smith, F.A., Reitz, R.H., 1987. Physiologically based pharmacokinetics and risk assessment process for methylene chloride. Toxicol. Appl. Pharmacol. 87, 185-205.

Bourne, D.W.A., 1995. Mathematical Modeling of Pharmacokinetic Data. Technomic Publishing Company, Inc, Lancaster, Penn.

Chen, C.J., Hsueh, Y.M., Tseng, M.P., Lin, Y.C., Hsu, L.I., Chou, W.L., Chiou, H.Y., Wang, I.H., Chou, Y.L., Tseng, C.H., Liou, S.H., 2001a. Individual susceptibility to arseniasis. In:
Chappell, W.R., Abernathy, C.O., Calderon, R.L. (Eds.), Arsenic Exposure and Health Effects IV. Elsevier, Oxford, UK, pp. 135-143.

Chen, C.M., Yu, S.C., Liu, M.C., 2001b. Use of Japanese medaka (Oryzia latipes) and tilapia (Oreochromis mossambicus) in toxicity tests on different industrial effluents in Taiwan. Arch. Environ. Contam. Toxicol. 40, 363-370.

Clewell III, H.J., 1995. The application of physiologically based pharmacokinetic modeling in human health risk assessment of hazardous substances. Toxicol. Lett. 79, 207-217.

Clewell III, H.J., Andersen, M.E., 1996. Use of physiologically based pharmacokinetic modeling to investigate individual versus population risk. Toxicology 111, 315-329.

Donohue, J.M., Abernathy, C.O., 1999. Exposure to inorganic arsenic from fish and shellfish. In: Chappell, W.R., Abernathy, C.O., Calderon, R.L. (Eds.), Arsenic Exposure and Health Effects. Elsevier, Oxford, UK, pp. 89-98.

Finney, D.J., 1978. Statistical Method in Biological Assay, third ed. Cambridge University Press, London, 508 pp.

Hermens, J.L.M., 1989. Quantitative structure-activity relationships of environmental pollutants. In: Hutzinger, O. (Ed.), Handbook of Environmental Chemistry, vol. 2E. Springer-Verlag Press, Berlin, pp. 111-162.

Hwang, P.P., Tsai, Y.N., 1993. Effects of arsenic on osmoregulation in the tilapia Oreochromis mossambicus reared in seawater. Mar. Biol. 117, 551-558.

Johnson, W., Finley, M.T., 1980. Handbook of Acute Toxicity of Chemicals to Fish and Aquatic Invertebrates, vol. 137. US Fish Wildlife Services Resource Publishing, pp. 1-98.

Koch, I., Reimer, K.J., Beach, A., Cullen, W.R., Gosden, A., Lai, V.W.M., 2001. Arsenic speciation in fresh-water fish and bivalves. In: Chappell, W.R., Abernathy, C.O., Calderon, R.L. (Eds.), Arsenic Exposure and Health Effects IV. Elsevier, Oxford, UK, pp. 115-123.

Kureishy, T.W., D'silva, C., 1993. Uptake and loss of mercury, cadmium and lead in marine organisms. Indian J. Exp. Biol. 31, 373-379.

Lalonde, R.L., 1992. Pharmacodynamics. In: Evans, W.E., Schentag, J.J., Jusko, W.J. (Eds.), Applied Pharmacokinetics. Lippincott Williams and Wilkins, New York, pp. 4-1-4-33.

Landrum, P.F., Harkey, G.A., Kukkonen, J., 1996. Evaluation of organic contaminant exposure in aquatic organisms: the significance of bioconcentration and bioaccumulation. In: Newman, M.C., Jagoe, C.H. (Eds.), Ecotoxicology: A Hierarchical Treatment. Lewis Publishers, Tokyo, pp. 85-131.

Lauren, D.J., McDonald, D.G., 1987a. Acclimation to copper by rainbow trout, Salmo gairdneri: physiology. Can. J. Fish. Aquat. Sci. 44, 99-104.

Lauren, D.J., McDonald, D.G., 1987b. Acclimation to copper by rainbow trout, Salmo gairdneri: biochemistry. Can. J. Fish. Aquat. Sci. 44, 105-111.

Liang, Y., Cheung, R.Y.H., Wong, H., 1999. Reclamation of wastewater for polyculture of freshwater fish: bioaccumulation of trace metals in fish. Water Res. 33, 2690-2700.

Liao, C.M., Chen, B.C., Lin, M.C., Chen, J.W., 2000. An optimal trace zinc biomonitor (Haliotis diversicolor supertexta) control system design in aquacultural ecosystems. Appl. Math. Model. 24, $27-43$.

Liao, C.M., Lin, M.C., 2001. Acute toxicity modeling of rainbow trout and silver sea bream exposed to waterborne metals. Environ. Toxicol. 16, 349-360.

Liao, C.M., Chen, B.C., Singh, S., Lin, M.C., Liu, C.W., Han, B.C., 2003. Acute and bioaccumulation of arsenic in tilapia (Oreochromis mossambicus) from a blackfoot disease area in Taiwan. Environ. Toxicol. 18, 252-259.

Liao, C.M., Tsai, J.W., Ling, M.P., Liang, H.M., Chou, Y.H., Yang, P.T., 2004. Organ-specific toxicokinetics and dose-response of 
arsenic in tilapia Oreochromis mossambicus. Arch. Environ. Contam. Toxicol. 47, 502-510.

Lien, G.J., McKim, J.M., Hoffman, A.D., Jenson, C.T., 2001. A physiologically based toxicokinetic model for lake trout (Salvelinus namaycush). Aquat. Toxicol. 51, 335-350.

Lin, M.C., Liao, C.M., Liu, C.W., Singh, S., 2001. Bioaccumulation of arsenic in aquacultural large-scale mullet Liza macrolepis from blackfoot disease area in Taiwan. Bull. Environ. Contam. Toxicol. 67, 91-97.

McCarty, L.S., Mackay, D., 1993. Enhancing ecotoxicological modeling and assessment. Environ. Sci. Technol. 9, 1719-1728.

Nichols, J.W., Jensen, K.M., Tietge, J.E., Johnson, R.D., 1998. Physiologically based toxicokinetic model for maternal transfer of 2,3,7,8-tetrachlorodibenzo-p-dioxin in brook trout (Salvelinus fontinalis). Environ. Toxicol. Chem. 17, 2422-2434.

Reitz, R.H., McCroskey, P.S., Andersen, M.E., Gargas, M.L., 1990. Development of a physiologically based pharmacokinetic model for risk assessment with 1,4-dioxane. Toxicol. Appl. Pharmacol. $105,37-54$.

Reyes-Sosa, C.F., Castellanos-Molina, R., 1995. Nutritional evaluation of gizzard erosion positive brown fish meal starter diets for Nile tilapia, Oreochromis niloticus. Aquaculture 138, 323-329.

Singh, S., 2001. A physiologically based pharmacokinetic and pharmacodynamic model for arsenic accumulation in aquacultural fish from blackfoot disease area in Taiwan. Unpublished PhD dissertation. National Taiwan University.

Sorensen, E.M.B., 1991. Metal Poisoning in Fish. CRC Press, Boston MA, pp. 367-379.

Sparks, T. (Ed.), 2000. Statistics in Ecotoxicology. Wiley, New York, NY, 320 pp.
Spehar, R.L., Fiandt, J.T., Anderson, R.L., Defoe, D.L., 1980. Comparative toxicity of arsenic compounds and their accumulation in invertebrates and fish. Arch. Environ. Contam. Toxicol. 9, $53-63$.

Suhendrayatna, Ohki, A., Nakajima, T., Maeda, S., 2002. Studies on the accumulation and transformation of arsenic in fresh organisms II. Accumulation and transformation of arsenic compounds by Tilapia mossambica. Chemosphere 46, 325-331.

Suner, M.A., Devesa, V., Munoz, O., Lopez, F., Montoro, R., Arias, A.M., Blasco, J., 1999. Total and inorganic arsenic in the fauna of the Guadalquivir estuary: environmental and human health implications. Sci. Total Environ. 242, 261-270.

Takeuchi, T., Lu, J., Yoshizaki, G., Satoh, S., 2002. Effect on the growth and body composition of juvenile tilapia Oreochromis mossambicus fed raw Spirulina. Fisheries Sci. 68, 34-40.

Thomann, R.V., Shkreli, F., Harrison, S., 1997. A pharmacokinetic model of cadmium in rainbow trout. Environ. Toxicol. Chem. 16, 2268-2274.

US EPA, 2000. Technical progress report of the implementation plan for probabilistic ecological assessments: aquatic systems. Meeting scheduled for April 6-7, US Environmental Protection Agency, Washington, DC

US FDA, 1993. Guidance Document for Arsenic in Shellfish. US Food and Drug Administration, Washington, DC, pp. 25-27.

de Vries, J., 1996. Toxicokinetic: quantitative aspects. In: Niesink, J.M., de Vries, J., Hollinger, M.A. (Eds.), Toxicology: Principles and Applications. CRC Press, New York, pp. 136-183.

Xie, S., Cui, Y., Liu, J., 1997. Effect of body size on growth and energy budget on Nile tilapia, Oreochromis mossambicus. Aquaculture 157, 25-34. 